\title{
INHERITANCE AND MAPPING OF VICILIN STORAGE PROTEIN GENES IN PISUM SATIVUM L
}

\author{
SAYED H. MAHMOUD AND JOHN A. GATEHOUSE \\ Department of Botany, Durham University, South Road, Durham, DH1 3LE, U.K. \\ Received 13.xii.83
}

\section{SUMMARY}

Gel electrophoresis techniques have been used to investigate genetically controlled variation in the major subunits $(\mathrm{Mr} 50,000)$ of vicilin, a storage protein of Pisum sativum $\mathrm{L}$. The $\mathrm{F}_{1}$ protein band patterns were shown to be additive with respect to those of the parental lines and to be identical in reciprocal crosses. Genetic analysis of the $F_{2}$ plants indicated that the $50,000 \mathrm{Mr}$ vicilin subunit band pattern is controlled by a pair of co-dominant genes at single locus. The $F_{2}$ data were used to locate this major vicilin gene locus $(V c-1)$ to chromosome 7 , closely linked to the $r$ locus (for round and wrinkled seed surface).

\section{INTRODUCTION}

Genetic variation in band patterns of the seed proteins of pea (Pisum sativum L.) on gel electrophoresis has been observed for both the major storage proteins, vicilin (Hynes, 1968) and legumin (Davies, 1973). In the case of vicilin, it was shown that $F_{1}$ seed protein band patterns arose from the additive patterns of the two parental types (i.e., that vicilin protein molecules were inherited additively) and that the patterns were controlled by alternative alleles at a single locus. Further vicilin loci were identified by Thomson and Schroeder (1978) by carrying out gel electrophoresis under differing conditions, and the use of denaturing conditions allowed some of the vicilin loci to be identified with the "subunits" or component polypeptides of the protein. These results showed that in reciprocal crosses between two lines of peas, band patterns of vicilin from $F_{2}$ seeds segregated in a 1:2:1 parent A: additive: parent $B$ ratio on gel electrophoresis, indicating that vicilin band patterns were controlled by pairs of co-dominant genes at single loci. The loci were not identified with the one demonstrated by Hynes (1968), nor was the relationship between the putatively different vicilin loci explored, although they were claimed to correlate with vicilin structural genes on the pea genome. Of the three loci identified, one (" $V c a$ ") was subsequently identified with a related storage protein, convicilin (Matta and Gatehouse, 1982) while the others were identified with component polypeptides of vicilin of $\mathrm{Mr}<35,000$. None of the loci were mapped.

Elucidation of the synthesis of vicilin has shown that the initial products of the vicilin structural genes are $50,000 \mathrm{Mr}$ precursors, of differing amino acid sequences, some of which are proteolytically cleaved after translation is complete to yield the "subunits" or component polypeptides of $\mathrm{Mr}<$ 35,000 observed in the protein as isolated (Gatehouse et al., 1981, 1982). Variation in the $50,000 \mathrm{Mr}$ subunits of vicilin is thus most likely to reflect variation in the structural genes for the protein rather than to be a result of post-translational modification (which may not be simply related to protein structure). However, variation in vicilin $50,000 \mathrm{Mr}$ subunit band 
patterns on SDS-PAGE has not been reported. In contrast, the well-established genetic variation in the $\alpha$-subunits of legumin on SDS-PAGE (Casey, 1979) has led to the mapping of a legumin locus, $\mathrm{Lg}-1$, to chromosome 7 in the pea genome, near the $r$-tl segment, where $r$ (sometimes called $r a$ ) is the locus determining round $(R)$ or wrinkled $(r)$ seeds, and $t l$ is the locus determining the presence of tendrils $(T l)$ or leaflets $(t l)$ at the ends of the side-branches $(r \cdots 5 \cdots t l \cdots 17 \cdots L g-l)$ (Davies, 1980); Matta and Gatehouse, 1982). The latter authors also reported the mapping of the genetic locus for the storage protein related to vicilin, convicilin $(C v c)$, to a segment of chromosome 2 on the pea genome $(s \cdots 18 \cdots C v c \cdots 3 \cdots k)$ where $s$ is the locus determining "sticky" (s) or "non-sticky" (S) seeds ("sticky" seeds adhere together in the pod), and $k$ is the locus determining normal $(\mathrm{K})$ or keel-like $(\mathrm{k})$ wings on the flowers. The pea genome $(4.8 \times$ $10^{9} \mathrm{bp}$ ) contains 7 chromosomes which range from $60-250$ cross-over units in length (Blixt, 1977); the above data shows that the storage protein loci mapped are independent.

The present communication reports the mapping of a putative vicilin structural gene locus $(V c-1)$ based on genetic variation in vicilin $50,000 \mathrm{Mr}$ subunit band patterns on SDS-PAGE.

Key To Gene Symbols (From The Pisum-Genebank Gene-Symbols, Blixt, S., Weibullsholm Plant Breeding Institute, Landskrona, Sweden (1981))

$\begin{array}{ll}a ; & \text { absence of anthocyanin pigments (white flowers) } \\ B r ; & \text { presence of bracts on flowers } \\ b t ; & \text { pod apex pointed } \\ C v c ; & \text { convicilin SDS-PAGE band position } \\ D ; & \text { presence of axil colour } \\ d t ; & \text { short peduncle to first fiower } \\ F, F s ; & \text { seed testa with sharp, small violet spots } \\ f l ; & \text { absence of flecking (air pockets) on leafiets and stipules } \\ i ; & \text { seed cotyledons green (I: yellow) } \\ K p ; & \text { keel coloured with anthocyanin } \\ l e ; & \text { short internodes (dwarf habit) } \\ L g-1 ; & \text { legumin major } \alpha \text {-subunits band pattern on SDS-PAGE } \\ M ; & \text { brown marbling of seed testa } \\ m i f o ; & \text { close-set small and shallow impressions on testa } \\ P l ; & \text { black hilum colour on seeds } \\ r ; & \text { wrinkled seed character (R; round) } \\ t d ; & \text { no dentation on leaflets } \\ T r a ; & \text { tragacanth on inside of testa (oily spot) } \\ V c-1 ; & \text { vicilin } 50,000 \text { Mr polypeptide band pattern on SDS-PAGE } \\ w s p ; & \text { waxless except upper surface of leaflets }\end{array}$

Gene symbols with first letter capital indicate phenotypes dominant or codominant over the normal phenotype; others recessive

\section{MAterials AND MEthods}

Seeds of pea lines from the Weibullsholm collection (identified by number) were supplied by Dr S. Blixt, Landskrona, Sweden as were $F_{2}$ seeds from a cross of lines 360 and 611 . In addition, seeds of a number of isogenic pairs of pea lines differing only at the $r$ locus within each pair were supplied by Dr A. E. Slinkard. Reciprocal crosses between pea lines 1263 and 3080 were made, and the $F_{1}$ and $F_{2}$ progeny grown under greenhouse conditions at the Botanic Garden, Durham. 


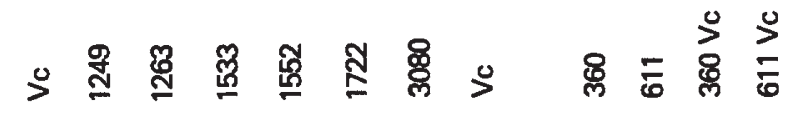

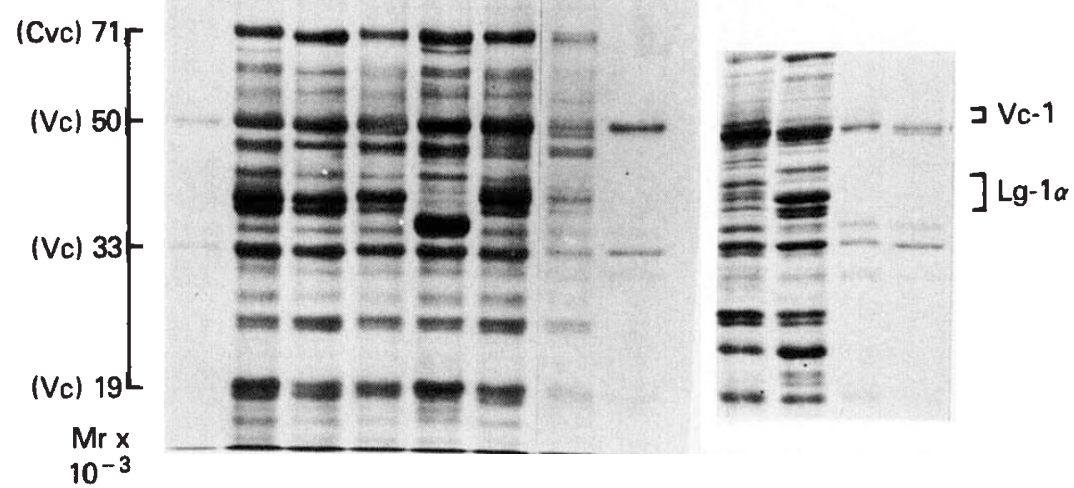

Plate 1. SDS-polyacrylamide gel electrophoresis (12 per cent acrylamide gel) of total protein extracts of seeds of different lines of peas (numbered), ( $400 \mu \mathrm{g} \mathrm{meal} / \mathrm{track})$ and of vicilin from line Feltham First $(\mathrm{Vc})$ and from lines 360 and $611(360 \mathrm{Vc}, 611 \mathrm{Vc}$ ? $(20 \mu \mathrm{g}$ protein/track). Variation in vicilin $50,000 \mathrm{M}(\mathrm{Vc}-1)$ and legumin $\alpha$-subunit (Lg-1) band patterns is indicated. 


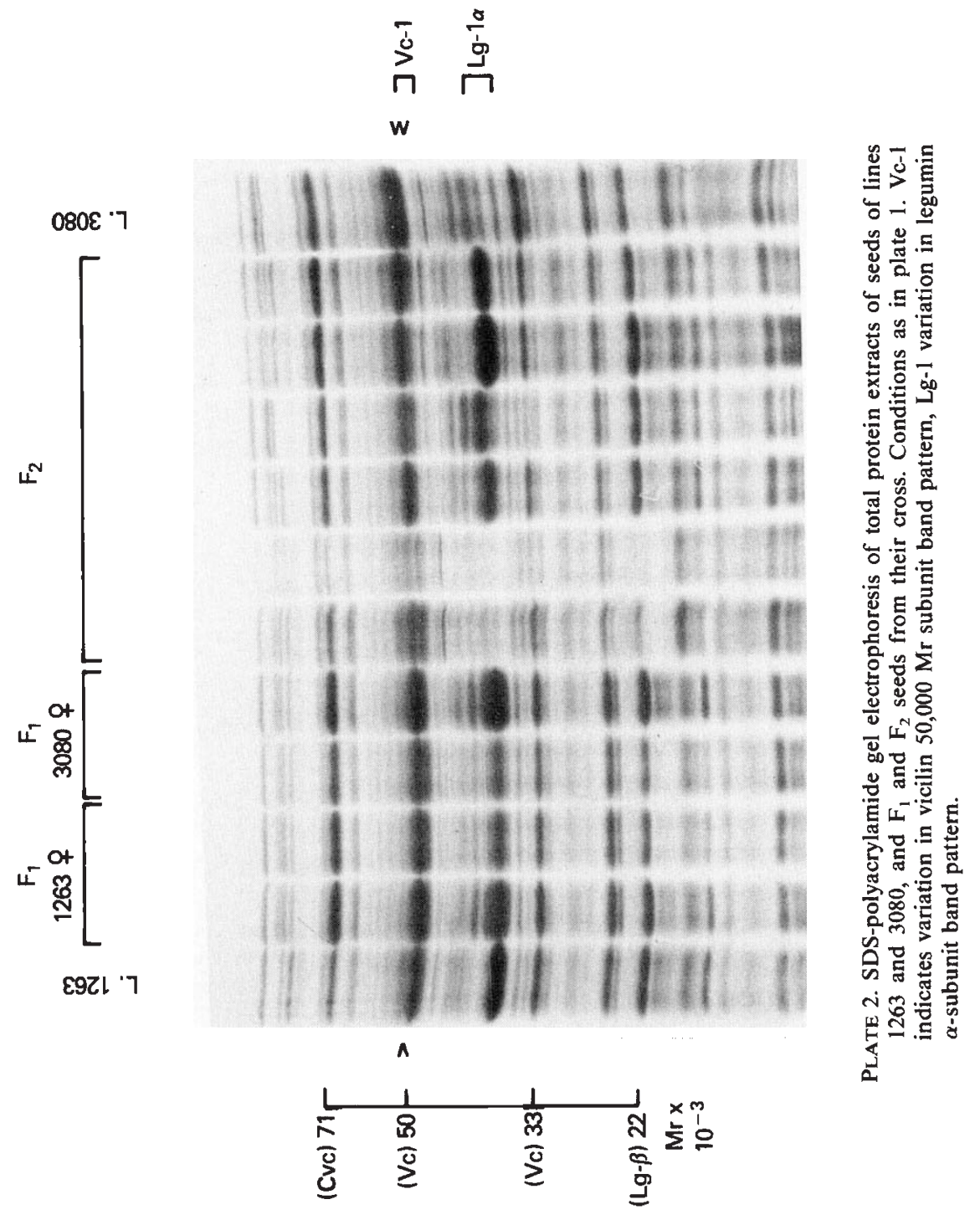




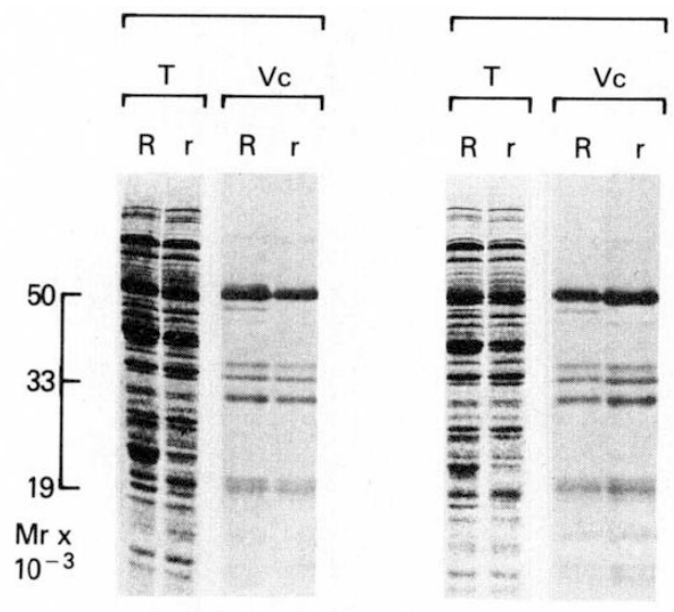

PLATE 3. SDS-polyacrylamide gel electrophoresis (17 per cent acrylamide gel) of total protein extracts of seeds from isogenic round/wrinkled pea lines $(T)$, compared with corresponding "Western" blots of vicilin subunits $(\mathrm{Vc})$. $\mathrm{R}$ indicates round seed phenotype, $\mathrm{r}$ wrinkled seed phenotype. Other conditions as in plate 1 . 
Total protein extracts of single or half mature pea seeds were made and analysed by SDS-polyacrylamide gel electrophoresis on 12 per cent acrylamide gels as previously described (Matta et al., 1981; Laemmli, 1970). Vicilin subunit bands were transferred from SDS polyacrylamide gels to nitrocellulose paper by electro-blotting, and were subsequently detected using affinity-purified antivicilin IgG, goat anti-rabbit IgG (peroxidase conjugated) and staining with 4-chloro-1-naphthol according to standard protocols (Towbin et al., 1979).

Chi-square values were calculated according to Fisher (1925). The $F_{2}$ segregation data were used to give crossing over values by the "product ratio" method of Immer (1930).

\section{Results}

\section{(i) Variation in vicilin subunit band patterns}

Plate 1 shows the total protein subunit band patterns of different pea lines. In general, little variation in the band patterns of vicilin subunits at approx. $50,000 \mathrm{Mr}$ or $33,000 \mathrm{Mr}$ was observed, in contrast to the pronounced variation in legumin $\alpha$ subunits ( 4 different patterns in 8 lines tested) and frequent, although less pronounced, variations in the convicilin band ( 3 different patterns in 8 lines tested). However, line 3080 showed a double band at $50,000 \mathrm{Mr}$ whereas all other lines showed a single thicker band; the latter pattern was also given by a further 8 lines screened. Line 611 gave a double banded pattern similar to 3080 . No variation in the vicilin $33,000 \mathrm{Mr}$ "subunits" was observed in this study, and variations in other vicilin polypeptides were not examined. A cross of lines 3080 and 1263 was selected as suitable for testing the segregation between the variation in vicilin band pattern and that in legumin $\alpha$ subunits; in addition, the seed surface round/wrinkled gene $r$ differed between these lines (Genotypes: $1263=a$, $B r, d t, T r a ; 3080=a, r, l e) . \mathrm{F}_{2}$ seeds from a cross of lines 360 and 611 were also examined (Genotypes $360=a, w s p, f l, b t$, mifo, Tra, $i, r ; 611=K p, t d$, $D, P l, M, F, F s)$.

\section{(ii) Inheritance of vicilin 50,000 $\mathrm{Mr}$ subunit}

Ten $F_{1}$ seeds from each reciprocal cross of lines 1263 and 3080 showed additive inheritance patterns for the vicilin 50,000 Mr subunit band pattern; the $F_{1}$ patterns were the same irrespective of which parent was the male parent and no segregation was observed (see plate 2). These results indicate that there is no maternal effect in the inheritance of the major vicilin subunit and the parental lines were homozygous. $308 \mathrm{~F}_{2}$ seeds were examined, and showed the expected monogenic inheritance and dominance of the $r$ gene (table 1). The segregation of the band patterns for the $\alpha$ subunits of legumin and the vicilin $50,000 \mathrm{Mr}$ subunits in the $F_{2}$ seeds is shown in plate 2 . The observed frequencies of the parental and hybrid band patterns of the legumin $\alpha$ - and vicilin $50,000 \mathrm{Mr}$ subunits are given in table 1 , and support the hypothesis that the vicilin $50,000 \mathrm{Mr}$ subunit band pattern is controlled by a single pair of co-dominant alleles, like that $(L g-1)$ controlling the legumin $\alpha$-subunit band pattern. This locus is subsequently referred to as $V c-1$. That the observed variation in band patterns was actually due to vicilin polypeptides was confirmed by transfer of the protein subunits from an SDS-PAGE 
TABLE 1

Observed frequency, $\chi^{2}$ values and probability range of the characters studied in the $F_{2}$ progeny of the cross " $1263 \times 3080$ "

\begin{tabular}{|c|c|c|c|c|}
\hline Character & obs & $\begin{array}{l}\text { classes a } \\
\text { rved frequ }\end{array}$ & & $\chi^{2}$ \\
\hline $\begin{array}{l}\text { Vicilin } 50,000 \mathrm{Mr} \\
\text { subunit }(V c-1)\end{array}$ & $\begin{array}{c}V c^{(1263)} \\
68\end{array}$ & $\begin{array}{l}V c^{\left(F_{1}\right)} \\
160\end{array}$ & $\begin{array}{c}V_{c-1} 1^{(3080)} \\
80\end{array}$ & $1.40^{\mathrm{ns}}$ \\
\hline $\begin{array}{l}\text { Legumin } \alpha \\
\text { subunit }(L g-1)\end{array}$ & $\begin{array}{l}L g \cdot 1^{(1263)} \\
84\end{array}$ & $\begin{array}{l}\operatorname{Lg} \cdot 1^{\left(F_{1}\right)} \\
158\end{array}$ & $\begin{array}{l}\operatorname{Lg}-1^{(3080)} \\
66\end{array}$ & $2 \cdot 31^{\mathrm{ns}}$ \\
\hline $\begin{array}{l}\text { Seed surface } \\
(R / r)\end{array}$ & $\begin{array}{l}R^{(1263)} \\
238\end{array}$ & $\begin{array}{c}r^{(3080)} \\
70\end{array}$ & - & $0.84^{\mathrm{ns}}$ \\
\hline
\end{tabular}

analysis of total extracts of parental, $F_{1}$ and $F_{2}$ seeds to nitrocellulose and specific detection of vicilin polypeptides by antivicilin IgG ("Western" blotting). A strong reaction was observed with the variant 50,000 Mr subunits (data not presented). Other vicilin polypeptides which reacted with the antivicilin IgG were invariant.

\section{(iii) Mapping the vicilin gene locus}

In order to establish whether or not the genetic locus for the vicilin $50,000 \mathrm{Mr}$ subunit band pattern was linked to the markers $r$ and $L g-1$, the $\mathrm{F}_{2}$ data were used to calculate crossover values (table 2). No recombinants were observed between the $V c$-1 pattern of line 1263 and wrinkled seed surface $(r)$ leading to a crossover value of 0 between the $V c$-1 and $r$ loci, and suggesting that these genes are closely linked to the extent of being within less than 2 crossover units of each other. In confirmation of earlier results, the major legumin gene $L g-1$ was found to be linked to gene $r$ on chromosome 7 (crossover value $36 \cdot 2 \pm 4 \cdot 9$ ). A crossover value of $29 \cdot 5 \pm 3 \cdot 3$ between $L g-1$ and $V c-1$ was also determined; in this case the genes are in coupling phase (table 2) so this figure is likely to be more accurate. No linkage to other genes segregating in this cross was observed. Examination of $181 \mathrm{~F}_{2}$ seeds from the cross of lines 360 and 611 also showed no recombinants between the wrinkled seed surface $r$ phenotype and line $611(V c-1)$ pattern, and gave a crossover value of 16.2 $23 \cdot 1$ per cent between $L g-1$ and $V c-1$ (coupling phase), in reasonable agreement with data from the other cross. Although these lines are known to contain transpositions involving chromosome 7 (Blixt, 1977) it is most unlikely that this would affect the very close linkage between $V c-1$ and $r$.

The close linkage of the vicilin locus $V c$-1 with the $r$ locus was further supported by examination of seeds from pairs of isogenic lines differing at the $r$ locus. SDS-polyacrylamide gel electrophoresis of total protein extracts of these seeds showed that within each pair band patterns were identical, except that in 3 out of the 5 isogenic pairs examined one member of the 


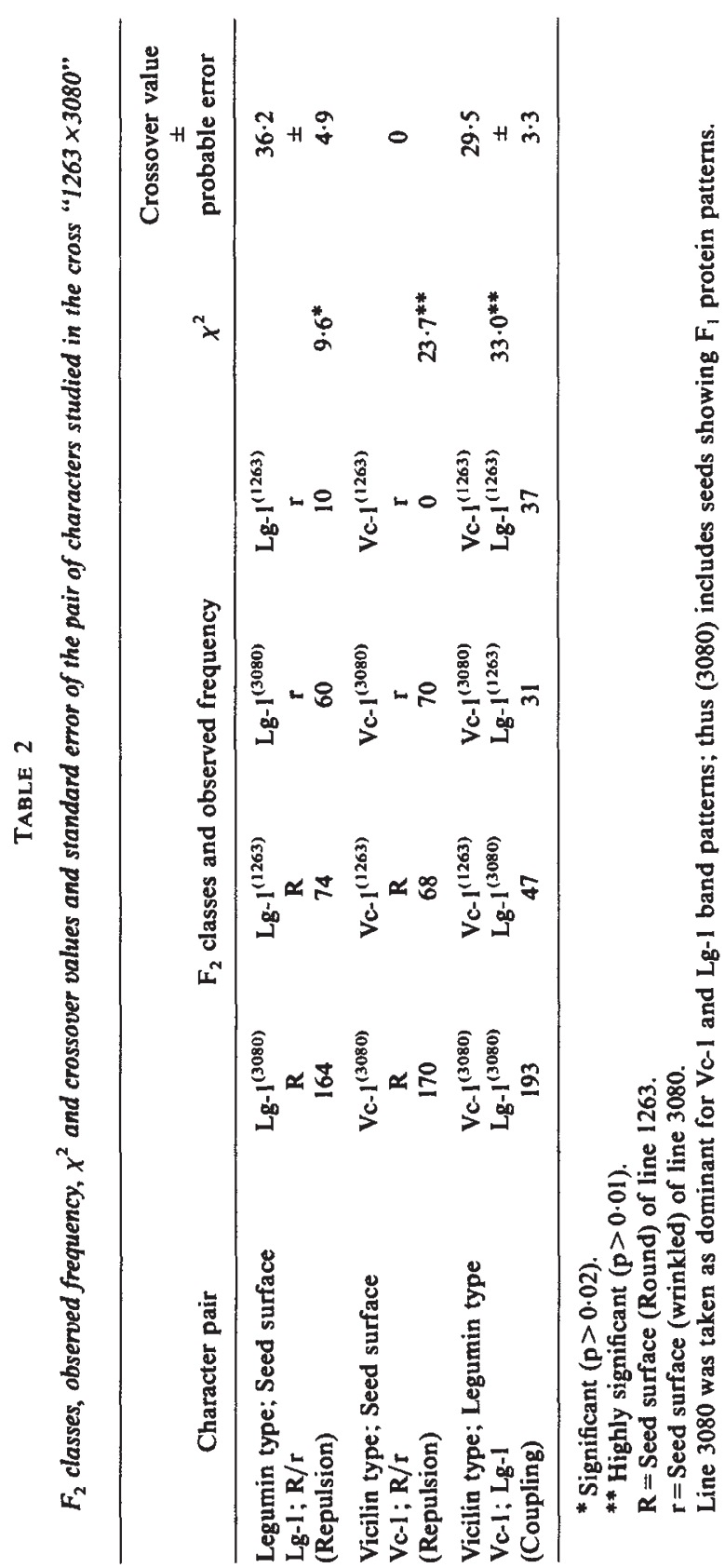


pair had an extra band in the vicilin 50,000 $\mathrm{Mr}$ region, at approx. $48,000 \mathrm{Mr}$ (plate 3 ). This band reacted with antivicilin IgG after transfer to nitrocellulose using a "Western" blotting procedure. Since these seeds were $F_{8}$ selections, $V c-1$ and $r$ must be closely linked for the different phenotypes at the two loci to have segregated together. Although an exact figure cannot be calculated from the small sample analysed, $V c-1$ and $r$ are suggested to be within 10 crossover units of each other, since this distance implies co-segregation in approx. 50 per cent of $F_{8}$ selections, assuming the parental lines differed in both their $V c-1$ and $r$ phenotypes.

\section{Discussion}

The locus identified in the present study is likely to represent a structural gene for vicilin for the reasons discussed above, i.e., that the observed difference in $50,000 \mathrm{Mr}$ subunit band patterns corresponds most nearly of all vicilin polypeptides to the initial translation products, and thus to genomic coding sequences. It is possible, however, that the differences in $50,000 \mathrm{Mr}$ subunit band patterns observed on SDS-PAGE are the result of some kind of post-translational modification not determined by structural genes, e.g. differences in carbohydrate side chains, but this is unlikely since the carbohydrate moiety of vicilin is known to be associated almost exclusively with the $16,000 \mathrm{Mr}$ polypeptide (Davey et al., 1981). This locus relates to a polypeptide different from those associated with the loci identified by Thomson and Schroeder (1978), although because of the precursor-product relationships of vicilin polypeptides of approx. $50,000 \mathrm{Mr}$ and less than $35,000 \mathrm{Mr}$ respectively, it is not necessarily different from their loci "Vcb" or "Vcc". The symbol $V c-1$ is used in accordance with the recommendations of the Pisum Genetics Association (Blixt, 1977) to allow for further loci, if shown to be distinct when mapped, to be designated $V c-2$, etc.

Further vicilin loci are possible, since vicilin is known to be encoded by a small family ( $<10$ copies) of genes on the pea chromosome (Gatehouse et al., 1983; Lycett et al., 1983). Legumin subunits, which are also encoded by a small gene family (3-4 members; Croy et al., 1982) map to more than one locus, (Casey, 1979; Matta and Gatehouse, 1982). However, some or all of the vicilin structural genes may be arranged in one or more closely linked arrays which would result in the number of "classical" vicilin loci being considerably fewer than the number of genes determined by DNA hybridisation. The present vicilin locus is not closely associated with either legumin or convilinin loci and thus vicilin gene expression must be controlled independently of the other storage proteins.

Close linkage of the vicilin locus with the $r$ locus is interesting in view of reports that the legumin: vicilin ratio in peas is affected by the round/wrinkled genotype (Davies, 1980, Schroeder, 1982), although the actual amounts of legumin in $\mathrm{mg}$ per seed does not differ significantly between round and wrinkled lines (Schroeder, 1982). It is thus perhaps tempting to postulate a direct effect of the $r$ locus genotype on vicilin synthesis, as was suggested for legumin synthesis (Davies, 1980); however, even if this were the case, the pleiotropic effects of the wrinkled phenotype (Shia and Slinkard, 1977) would make the existence of such a direct control very difficult to demonstrate. 
Acknowledgements. The authors would like to express their gratitude to Dr S. Blixt and Dr A. E. Slinkard for supplying seed material and to D. Bown and P. Preston for technical assistance. The assistance of the staff of the greenhouse in the Botanic Garden, Durham University, especially S. Grey, is also gratefully acknowledged. S. M. acknowledges financial support from the Egyptian Government.

\section{REFERENCES}

BLIXT, S. 1977. The gene symbols of Pisum. Pisum News Letter, 9, Supplement 2-63.

CASEY, R. 1979. Genetic variability in the structure of the $\alpha$-subunits of legumin from Pisum-a two dimensional gel electrophoresis study. Heredity, 43, 265-272.

CROY, R. R. D., LYCETT, G. W., GATEHOUSE, J. A., YARWOOD, J. N. AND BOUTER, D. 1982. Cloning and analysis of cDNA encoding plant storage protein precursors. Nature, 295, 76-79.

DAVEY, R. A., HIGGINS, T. J. V. AND SPENCER, D. 1981. Homologies between two small subunits of vicilin from Pisum sativum. Biochem. Internat., 3, 595-602.

DAVIES. D. R. 1973. Differential activation of maternal and paternal loci in seed development. Nature, (New Biol.), 245, 30-31.

DAVIES, D. R. 1980. The ra locus and legumin synthesis in Pisum sativum. Biochem. Genet., $18,1207-1219$.

FISHER, R. A. 1925. Statistical Methods for Research Workers. Oliver and Boyd, Edinburgh.

GAtehouse, J. A., CROY, R. R. D., MORTON, H., TYLER, M. AND BOUlTER, D. 1981. Characterisation and subunit structure of the vicilin storage proteins of pea (Pisum sativum L). Eur. J. Biochem., 118, 627-633.

GATEHOUSE, J. A., LYCETT, G. W., CROY, R. R. D., AND BOULTER, D. 1982. The post-translational proteolysis of the subunits of vicilin from pea (Pisum sativum L.). Biochem. J., 207, 629-632.

GATEhouse, J. A., LYCETT, G. W., DELAUNEY, A. J., CROY, R. R. D. AND BOULTER, D. 1983. Sequence specificity of the post-translational cleavage of vicilin, a seed storage protein of pea (Pisum sativum L.). Biochem. J., 212, 427-432.

HYNES, M. J. 1968. Genetically controlled variants of storage protein in Pisum sativum. Aust. J. Biol. Sci., 21, 827-829.

IMMER, F. R. 1930. Formulae and table for calculating linkage intensities. Genetics, 15, 81-98.

LAEMMLI, U. K. 1970. Cleavage of structural proteins during the assembly of the head of bacteriophage T4. Nature (London), 227, 680-685.

LYCETT, G. W., DELAUNEY, A. J., GATEHOUSE, J. A., GILROY, J., CROY, R. R. D. AND BOULTER, D. 1983. The vicilin gene family of pea (Pisum sativum L.): a complete cDNA coding sequence for preprovicilin. Nuc. Acids Res., 11, 2367-2380.

MATTA, N. K., GATEHOUSE, J. A. AND BOULTER, D. 1981. Molecular and subunit heterogeneity of legumin of Pisum sativum L. (parden pea) multi-dimensional gel electrophoretic study. J. Exp. Bot., 32, 1295-1307.

MATTA, N. K. AND GATEhOUSE, J. A. 1982. Inheritance and mapping of storage protein genes in Pisum sativum L. Heredity, 48, 383-392.

SCHROEDER, H. E. 1982. Quantitative studies on the cotyledonary proteins in the genus Pisum. J. Sci. Food Agric., 33, 623-633.

SHIA, G. AND SLINKARD, A. E. 1977. Relationship of seed shape and cotyledon colour to percent protein in peas. Crop Science, 17, 183-184.

THOMSON, J. A. AND SCHROEDER, H. E. 1978. Cotyledonary storage proteins in Pisum sativum. II. Hereditary variation in components of the legumin and vicilin fractions. Aust. J. Plant Physiol., 5, 281-294.

TOWBIN, H., STAEHELIN, T. AND GORDON, J. 1979. Immuno-assay by antibody blot. Proc. Nat. Acad. Sci., USA, 76, 4350-4354. 